\title{
Summary of a systematic review on oral nutritional supplement use in the community
}

\author{
Rebecca J. Stratton \\ Wolfson College, University of Cambridge, Cambridge CB3 9BB, UK
}

\begin{abstract}
Despite a marked increase in the prescription of oral nutritional supplements (ONS) in the community (Department of Health, 1991-7), there is still uncertainty about the value of their use in patients with different diseases. To answer questions about the effects on ONS on body weight and structure, spontaneous food intake and body function, a critical systematic review was undertaken (Stratton \& Elia, 1999a). Eighty-four trials were reviewed (forty-five randomized, thirty-nine non-randomized; 2570 patients; diagnoses including chronic obstructive pulmonary disease, Crohn's disease, cystic fibrosis, human immunodeficiency virus and acquired immune deficiency syndrome and cancer). Most studies $(83 \%)$ were conducted in patients living at home. The supplements were typically mixed macronutrients in liquid form, providing $<0.42-10.5 \mathrm{MJ} / \mathrm{d}$ for 1 week-2 years. The studies reviewed in patients with predominantly chronic conditions living in the community suggested that: (1) ONS produce demonstrable clinical (including functional) benefits, but the nature and extent of these benefits varies with the underlying chronic condition; (2) ONS increase total energy intake with $>50 \%$ of the energy from ONS typically additional to that from habitual food intake; (3) improvements in body weight, total energy intake and body function following ONS appear to occur more frequently in individuals with a BMI $<20 \mathrm{~kg} / \mathrm{m}^{2}$ than in those with a BMI $>20 \mathrm{~kg} / \mathrm{m}^{2}$.
\end{abstract}

Oral supplementation: Patients in the community

Oral nutritional supplements (ONS) are increasingly being used in the community in a diverse range of patients suffering from diseases (e.g. chronic obstructive pulmonary disease (COPD), cystic fibrosis, cancer, human immunodeficiency virus and acquired immune deficiency syndrome, and liver and gastrointestinal disease) that may impair appetite and food intake (Plata-Salaman, 1996; Tisdale, 1997), and ultimately affect body weight and nutritional status (Schurch \& Scrimshaw, 1987; James \& Ralph, 1992; Ramsey et al. 1992; Elia \& Lunn, 1996). There are a huge number of ONS (liquid sip-feeds, bars, puddings, powders) in use in clinical practice. They are typically macronutrient supplements (carbohydrate, protein, fat), which may also contain vitamins, minerals and trace elements. Many ONS are prescribable, and indeed there has been a notable increase in the number of prescription items for enteral nutrition in recent years (British National Formulary Section 9.4.2; Department of Health, 1991-7), mostly attributable to ONS (Department of Health, 1991-7). The cost implications to the National Health Service are significant, with total expenditure on ONS exceeding $£ 1.5$ million in 1997. Also,
ONS are now being used more commonly in the community than in hospitals. However, it is startling to find that there is little agreement about the value of such supplements in patients with different diseases or conditions living in the community. Furthermore, as a consequence there are no generally agreed recommendations for their use. Before such recommendations can be made, fundamental questions about the effects of oral supplements on body weight and/or composition, habitual food intake and, most importantly, body function in different clinical situations need to be systematically addressed.

In particular, one outstanding issue is whether the energy consumed as a supplement merely suppresses appetite and food intake, replacing the energy habitually taken from food, and so failing to substantially increase total energy intake. If there is no increase in total energy intake, then improvements in body weight, composition and function may not follow. If the supplement replaces normal food intake, then the cost of the supplement prescription is effectively 'purchasing' food. In contrast, if the energy of the supplement is additional to that from habitual food 
intake, then improvements in body weight, and possibly function, may follow. The extent to which artificial nutrition (Stratton \& Elia, 1999b), and in particular ONS, suppresses appetite and food intake may depend on the consistency (solid v. liquid; Pliner, 1973; Malagelada et al. 1979; Kissileff, 1985) or the composition (macronutrient content, energy density; Stubbs, 1992; Poppit \& Prentice, 1996; Stubbs et al. 1998) of the supplement and the times and frequency of consumption.

As the available information on the effects of use of ONS in the community setting had not previously been amalgamated to address the issues mentioned earlier, a critical systematic review of studies conducted to assess the effects of ONS in different groups of patients living in the community was undertaken (Stratton \& Elia, 1999a). Specific questions addressed by the review included: (1) what effect do ONS have on body structure and weight? (2) what effect do ONS have on total energy intake, spontaneous food intake and appetite? (3) what effect do ONS have on body function?

\section{Review methodology}

The systematic review was conducted according to explicit and reproducible methodology (Stratton \& Elia, 1999a). The searching methods used to locate relevant studies included computer-based databases (e.g. Medline SilverPlatter v.2 (January 1966-June 1998); Bath Information and Data Services (January 1981-June 1998); Cochrane Centre, Oxford), in addition to cross-referencing from reference lists and published papers, reviews and industrial information, discussion with health professionals and academic researchers in specialist areas and consultation with professional bodies (Dickersin et al. 1994; McManus et al. 1998). Inclusion criteria for studies were established (Table 1), specifying the population (e.g. patients), the intervention (e.g. types of ONS) and the outcome measures (e.g. body weight, function). All studies were independently categorized and coded according to study design by two investigators (Table 2). Due to the scarcity of randomized controlled trials in some groups, particularly in children with disease-associated growth failure (in whom placebo groups would not be ethically feasible), non-randomized trials were also included in the review.

Information on the number of patients studied (both supplemented and unsupplemented), their initial nutritional status, their disease or clinical condition, the duration of ONS and the type, composition and quantity of supplement given was gathered for each of the trials reviewed. A record was also made of a number of outcome measures following ONS. These outcome measures included:

body weight and structure; information on changes in body weight or BMI, lean body mass, fat mass, arm anthropometry and indices of growth were recorded;

total energy intake and food intake; changes in total energy intake observed during studies were recorded and quantified when the data was available. An estimation of the percentage of supplement energy that was additive to food energy was calculated where possible (Stratton \& Elia, $1999 a)$

body function; general functional outcomes, such as quality of life, well-being and hand-grip strength were noted in addition to disease-specific outcomes (e.g. respiratory muscle strength in patients with COPD).

\section{Summary of studies reviewed}

\section{Population}

Eight-four trials (2570 patients) were included in the systematic review to assess the effects of ONS consumption in disease-specific groups living in the community. Studies were grouped according to disease or condition as follows: COPD (fourteen trials), Crohn's disease (nine trials), cystic fibrosis (eleven trials), elderly (twelve trials), human immunodeficiency virus and acquired immune deficiency syndrome (fifteen trials); liver disease (two trials), malignancy (fifteen trials); other conditions (six trials). All supplementation studies were carried out in the community setting: $83 \%(n 70)$ were conducted in patients living at home and $4 \%(n 3)$ in residential homes; $8 \%(n)$ 7) were in patients who started in hospital and continued as outpatients; $5 \%$ ( $n$ 4) were partly or totally conducted in a research centre.

Table 2. Summary of trial designs and coding used in the systematic review

\begin{tabular}{llc}
\hline Coding & Design of study & No. of studies \\
\hline $\mathrm{A}^{1}$ & $\begin{array}{c}\text { Method of randomization documented; } \\
\text { complete follow-up }\end{array}$ & 7 \\
$\mathrm{~A}^{2}$ & $\begin{array}{c}\text { No method of randomization given; } \\
\text { complete follow-up }\end{array}$ & 25 \\
$\mathrm{~A}^{3}$ & $\begin{array}{c}\text { No method of randomization given; } \\
\text { incomplete follow-up }\end{array}$ & 13 \\
$\mathrm{~B}$ & $\begin{array}{l}\text { Non-randomized controlled } \\
\text { C }\end{array}$ & 10 \\
\hline
\end{tabular}

Table 1. Systematic review inclusion criteria for studies

1. Use of oral nutritional supplements: prescribable or non-prescribable; macronutrient supplements ( $\mathrm{CHO}$, fat, protein) in the form of commercial sip feeds, bars, puddings, powders reconstituted as drinks or added to food or drink; home-made supplements. Studies using nutritional supplements containing only branched-chain amino acids or micronutrients were excluded

2. Non-pregnant subjects of all ages

3. All studies must be 'community based': studies involving outpatients living at home or in a research centre; patients in long-term residential care. Studies in which supplementation was started in hospital and continued at home after discharge were included. Studies in developing countries were excluded

4. Randomized and non-randomized designs

$\mathrm{CHO}$, carbohydrate. 
Forty-five trials (54\% of the total; $n 1728$ patients) were randomized and thirty-nine trials ( $n 842$ patients) were not (see Table 3). Overall, studies tended to include small numbers of patients, as illustrated in Fig 1. Furthermore, only three of the eight-four trials reported the use of power calculations to indicate the necessary sample size needed to show a treatment effect (Evans et al. 1987; Chlebowski et al. 1993; Keele et al. 1997). In some cases study sample size was considered to be insufficient to detect significant changes in weight and other outcome measures (type II error). For example, simple power statistics (at $80 \%$ power; Altman, 1991), suggest that more than 120 subjects would be needed to detect a weight change of 1.5 (SD 3) kg.

\section{Intervention}

Liquid ONS were used (either commercial sip-feeds or powders reconstituted to form a liquid supplement) in more than $80 \%$ ( $n$ 67) of the studies reviewed. A minority of studies appeared to use solid supplements (bars, puddings; $n 2$ ), powders added to normal food and drink ( $n 1)$ and home-made (non-commercial) supplements $(n 4)$. In ten studies neither the name nor the type of supplement used was documented. The energy density of supplements varied considerably $(3 \cdot 25-16 \cdot 0 \mathrm{~kJ} / \mathrm{ml})$, as did their composition (protein-hydrolysate formulas, elemental formulas, medium-chain triacylglycerol-enriched, branched-chain amino acid-enriched and 'immuno-modulatory' formulas with extra arginine, $n-3$ fatty acids and nucleic acids). Standard formulas (approximately $15 \%$ energy as protein, $35 \%$ energy as fat and $50 \%$ energy as carbohydrate) were also commonly used. The amounts prescribed ranged from $<0.42 \mathrm{MJ} / \mathrm{d}$ to $>10.5 \mathrm{MJ} / \mathrm{d}$, for periods ranging from 1 week to over 2 years. Some studies ( $n$ 19) provided 'recommendations' to patients about when to consume the ONS, although it appeared that patient compliance with this timing was not checked. Suggested times varied considerably, and included between meals (Lipschitz et al. 1985; Woo et al. 1994; Volkert et al. 1996), with meals (Breslow et al. 1993), early in the morning (Cederholm \& Hellstrom, 1995), during the afternoon (Sondel et al. 1987) or in the evening (Fiatarone et al. 1994), with the aim to maximally increase total energy intake. Conclusions about the best time and frequency of ONS consumption in different disease groups could not be reached from the studies reviewed, in particular due to a lack of formal comparisons of these different schedules.

Table 3. Numbers of studies (and patients) in each disease category

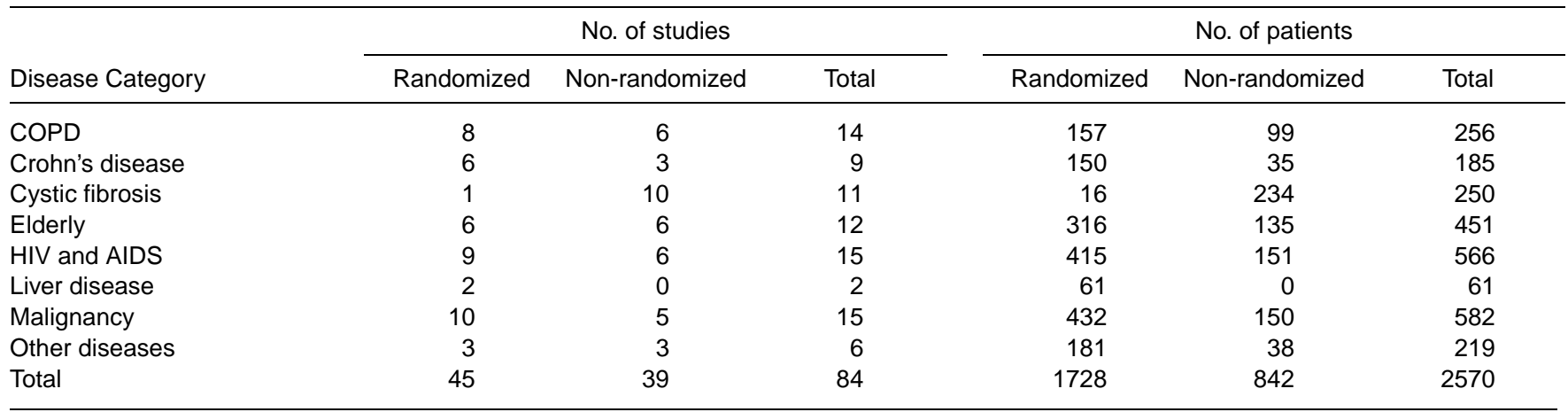

COPD, chronic obstructive pulmonary disease; HIV, human immunodeficiency disease; AIDS, acquired immune deficiency disease.

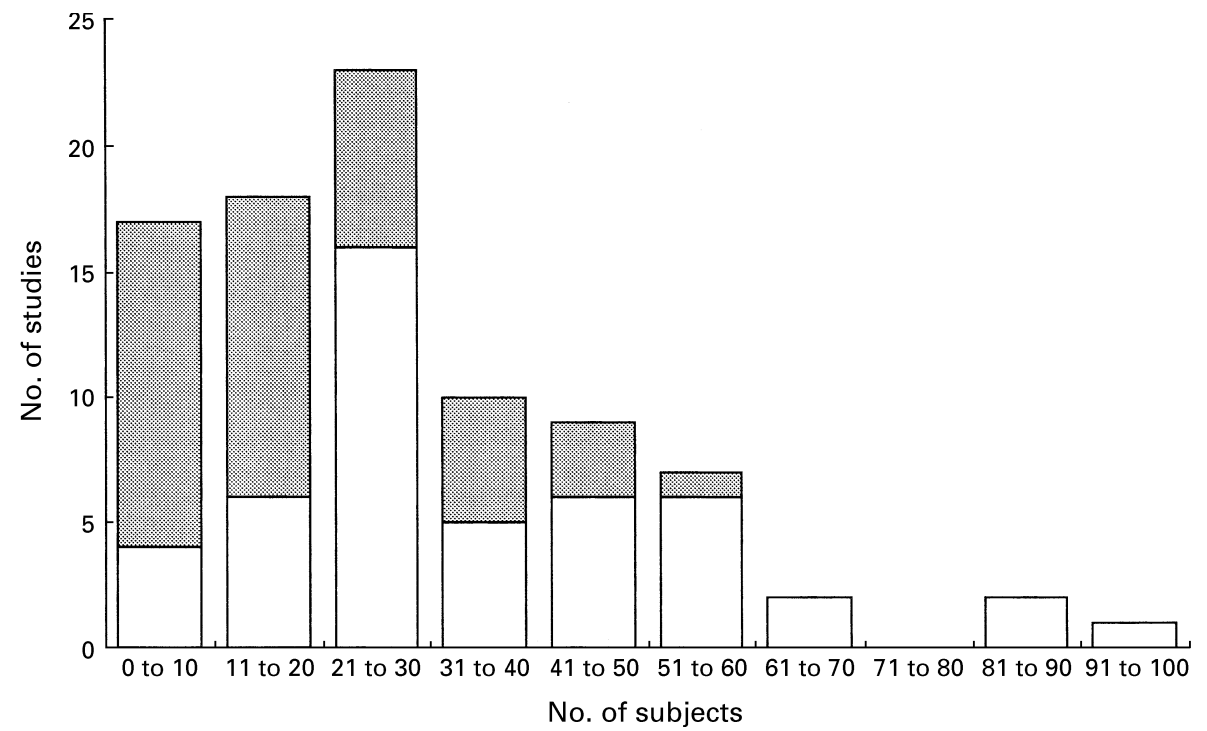

Fig. 1. The number of subjects in the randomized $(\square)$ and non-randomized $(\square)$ studies reviewed. 


\section{Outcome measures}

The systematic review set out to answer a number of questions about the effects of ONS on a variety of outcome measures in patients in the community, some of which will be addressed briefly.

What effect do oral nutritional supplements have on body structure and weight? Following ONS, weight gain varied considerably and depended on the duration and amount of supplementation, and the disease status of patients. Mean percentage weight change in supplemented patients compared with unsupplemented control patients could be calculated in twenty-two randomized controlled studies of adults (duration of ONS $10 \mathrm{~d}-1$ year, $n 900$ patients; Douglass et al. 1978; Foster et al. 1980; Elkort et al. 1981; Simko, 1983; Lewis et al. 1987; Norregaard et al. 1987; Efthimiou et al. 1988; Knowles et al. 1988; Arnold \& Richter, 1989; Donahoe et al. 1989; Otte et al. 1989; Fuenzalida et al. 1990; Nayel et al. 1992; Rogers et al. 1992; Hirsch et al. 1993; Fiatarone et al. 1994; Woo et al. 1994; Gray-Donald et al. 1995; Volkert et al. 1996; Jensen \& Hessov, 1997; Keele et al. 1997; Rabeneck et al. 1998). The mean percentage weight change of patients receiving ONS $(2.93 \%)$ was greater than that of the unsupplemented control patients $(1.15 \%$, mean difference 1.77 , range -2.69 to $9.2 \%$; weighted for the number of subjects in each category). Furthermore, of these studies, those in which supplemented patients had a mean BMI $<20 \mathrm{~kg} / \mathrm{m}^{2}$ (eleven studies) were associated with a greater percentage weight change $(4.7 \%$ of the body weight) than in those in which patients had a mean BMI $>20 \mathrm{~kg} / \mathrm{m}^{2}$ (2.4\% of the body weight; five studies). Similarly, the non-randomized studies showed that weight gain was greater in those patients with a mean $\mathrm{BMI}<20 \mathrm{~kg} / \mathrm{m}^{2}$ (mean $2.1 \mathrm{~kg}$ ) than in those with a mean BMI $>20 \mathrm{~kg} / \mathrm{m}^{2}$ (mean $1 \mathrm{~kg}$ ). It was also possible to summarize the effects of ONS on percentage weight change according to specific disease groupings. Fig. 2 shows the results expressed as $95 \%$ CI. Supplemented patients had

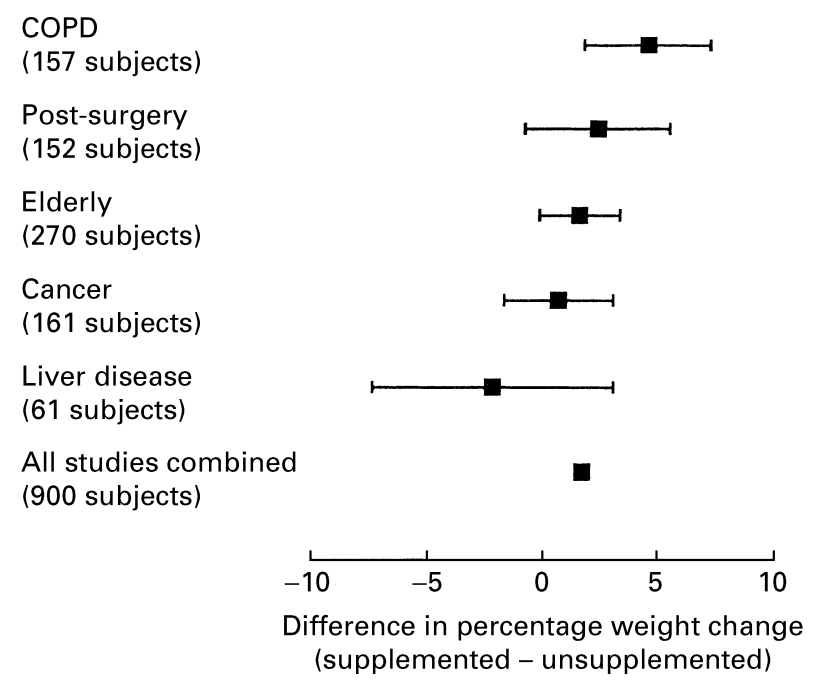

Fig. 2. Percentage weight change of supplemented $v$. control patients (grouped according to disease category). Values are means with $95 \% \mathrm{Cl}$ represented by horizontal bars. COPD, chronic obstructive pulmonary disease. greater weight gain (or less weight loss) than unsupplemented patients in all disease categories, except for liver disease. Indeed, the greatest difference in weight change between supplemented (ONS for 1-4 months; $+4.4 \%$ ) and unsupplemented patients $(-0.25 \%)$ occurred in those with COPD. This group of patients had a lower BMI than that of the other disease categories.

The impact of ONS on growth-retarded children (aged 4 months-19 years; diagnoses: cystic fibrosis, Crohn's disease, failure to thrive; $n 220$ ) could be evaluated in eleven of twelve studies reviewed. All studies showed improvements in growth, although in only seven trials were statistically significant improvements in weight or height centiles demonstrated (Allan et al. 1973; Berry et al. 1975; Yassa et al. 1978; Kirschner et al. 1981; Parsons et al. 1983; Shepherd et al. 1983; Skypala et al. 1998). Significant increases in muscle and fat mass were reported in approximately $50 \%$ (sixteen of thirty-seven) of studies that made measurements of body composition after ONS, but there was insufficient information to form conclusions about the effects of ONS on body composition in different disease groups.

Ultimately, it should be acknowledged that a large number of the trials reviewed did not document the nutritional status of patients $(n 40)$, ten studies failed to document the effect of ONS on body weight and more than $50 \%$ of studies did not attempt to measure body composition (and most of those that did only used upper-arm anthropometry). Furthermore, in most studies the presence or absence of oedema was not recorded, despite its potential to affect weight change.

What effect do oral nutritional supplements have on total energy intake, spontaneous food intake and appetite? Of the twenty-seven randomized controlled trials that assessed total energy intake, all showed an increase during ONS. The increase was evaluated to be statistically significant in only eighteen studies: surgery (Jensen \& Hessov, 1997; Keele et al. 1997); liver disease (Simko, 1983; Hirsch et al. 1993); cancer (Evans et al. 1987; Ovesen \& Allingstrup, 1992); the elderly (Meredith et al. 1992; Fiatarone et al. 1994; Woo et al. 1994); cystic fibrosis (Sondel et al. 1987) and Crohn's disease (Harries et al. 1983); COPD (Lewis et al. 1987; Norregaard et al. 1987; Efthimiou et al. 1988; Knowles et al. 1988; Fuenzalida et al. 1990; Rogers et al. 1992); other diseases (Kuhlmann et al. 1997). Although fourteen of sixteen non-randomized trials that assessed total energy intake showed an increase, in only seven was this increase statistically significant (Lynch et al. 1983; Parsons et al. 1983; Stauffer et al. 1986; Welch et al. 1991; Gray-Donald et al. 1994; Tolia, 1995; Skypala et al. 1998). The extent to which the energy from the ONS replaced or added to that from food could be assessed in seventeen trials, the results of which are summarized graphically in Fig. 3 (for details of methodology, see Stratton \& Elia, 1999a). Overall, the supplement energy was largely additional to that taken orally (mean increase in energy intake equivalent to $67 \%$ of the energy of the ONS consumed), but this contribution varied considerably according to the disease state and the BMI of patients (e.g. $79 \%$ of the ONS energy in those patients with a BMI $<20 \mathrm{~kg} / \mathrm{m}^{2}$ (eight studies); $28 \%$ of the ONS energy in those patients with a BMI $>20 \mathrm{~kg} / \mathrm{m}^{2}$ (five 
(a)

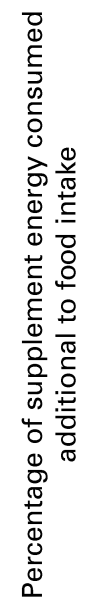

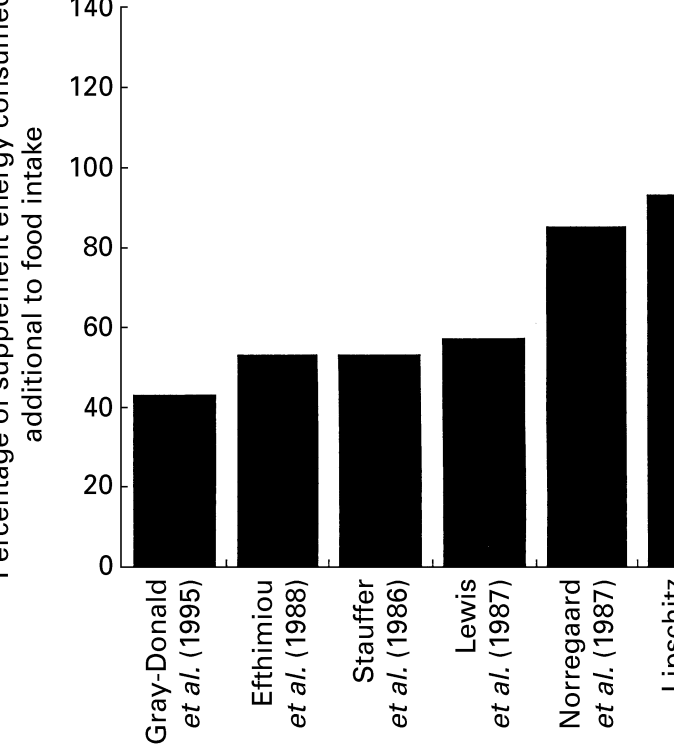

(b)

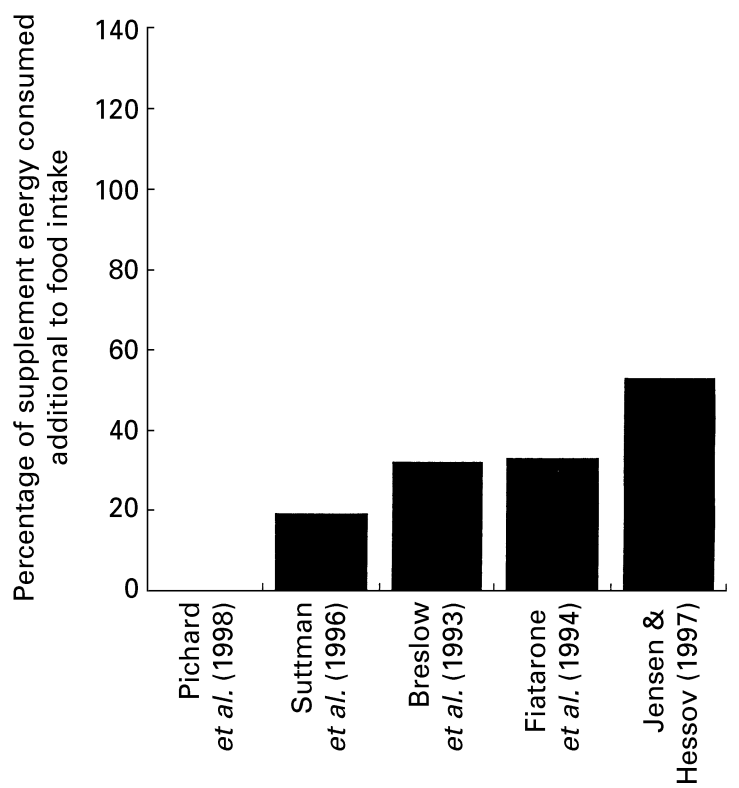

Fig. 3. Percentage of supplemented energy consumed that is additional to food intake, related to patients' BMI category: (a) patients' mean $\mathrm{BMI}<20 \mathrm{~kg} / \mathrm{m}^{2}$; (b) patients' mean BMI $>20 \mathrm{~kg} / \mathrm{m}^{2}$.

studies); Stratton \& Elia, 1999a). None of the studies reviewed formally assessed the impact of ONS on appetite sensations (such as hunger, fullness, desire to eat), although a variety of anecdotal observations were recorded, ranging from a loss of appetite to stimulation of appetite during the supplementation period.

However, in many studies there was limited information about the quantity, composition and type of ONS consumed. For example, in only $51 \%$ of randomized trials and $36 \%$ of non-randomized trials was it possible to calculate average supplement consumption. In addition, assessments of dietary and ONS intake were often undertaken infrequently (e.g. once per month) and over short periods of time (1-3d), and so may not have provided an accurate representation of the habitual dietary intake or ONS intake of the patients during the course of the investigation. The majority of studies also made no apparent attempts to estimate the validity of food and supplement intake records (e.g. no checks on the number of supplement cartons used).

What effect do oral nutritional supplements have on body function? Functional changes (assessed in fifty-nine studies) following ONS varied according to the disease or condition of patients, and were typically observed more commonly in those patients with a BMI $<20 \mathrm{~kg} / \mathrm{m}^{2}$ than in those with $\mathrm{BMI}>20 \mathrm{~kg} / \mathrm{m}^{2}$. Functional benefits included improved muscle strength, walking distance and well-being in patients with COPD (Wilson et al. 1986; Efthimiou et al. 1988; Donahoe et al. 1989; Rogers et al. 1992), improved growth performance in children with cystic fibrosis (Allan et al. 1973; Berry et al. 1975; Yassa et al. 1978; Kirschner et al. 1981; Parsons et al. 1983; Shepherd et al. 1983; Skypala et al. 1998), reduced falls (Gray-Donald et al. 1995) and increased activities of daily living (Volkert et al. 1996) in the elderly, and improvements in immune function in patients with human immunodeficiency virus (Hellerstein et al. 1994). It is possible that detriments due to ONS may occur in some overweight patients with certain diseases (e.g. cancer; Elkort et al. 1981; Evans et al. 1987). Despite the importance of functional outcomes, almost one-third of the studies reviewed appeared to have made no assessments of body function. Similarly, there was a lack of trials that reported the impact of ONS on the quality of life of the patients.

\section{Conclusions}

The critical systematic review (Stratton \& Elia, 1999a) aimed to comprehensively assess the existing research on the effects of ONS use in diverse patient groups in the community. A number of conclusions can be drawn from the studies reviewed, predominantly in patients with chronic conditions. First, the evidence base would suggest that ONS are associated with demonstrable clinical (including functional) benefits, although the nature and extent of these benefits varies with the underlying chronic condition. Second, improvements in body weight, total energy intake and body function following ONS appear to occur more frequently in individuals with a BMI $<20 \mathrm{~kg} / \mathrm{m}^{2}$ than in individuals with a BMI $>20 \mathrm{~kg} / \mathrm{m}^{2}$. However, it was difficult to pin-point subgroups of patients within trials who might benefit from ONS, such as those who were losing weight and had a BMI $>20 \mathrm{~kg} / \mathrm{m}^{2}$. This difficulty was due to a number of limitations in the data such as the collective presentation of results from heterogeneous groups of patients, the use of a variety of types and quantities of ONS and inappropriate study designs (small sample sizes, lack of randomization). What also remains to be determined is whether such clinical benefits could also be achieved by means other than ONS, such as dietetic counselling and food intervention. With the information obtained from the systematic review, recommendations for the use of ONS in clinical practice in the community have been made (Stratton 
\& Elia, 1999a). Finally, there are a number of outstanding areas for research in the future. Controlled comparisons of the efficacy of different forms of therapy to increase dietary intake and improve body weight and function (ONS, behavioural therapy, dietary counselling and combinations of these therapies) are required. Studies also need to be undertaken to establish the type, palatability and size of ONS, as well as the timing and frequency of consumption, that is required to produce optimal short-term and long-term effects on appetite, food intake and clinically-relevant outcome measures, including nutritional status and physical and psycho-social function. Furthermore, studies in the community setting need to be extended to include patients with a range of conditions, including those for which there is little information (e.g. diseases in children, neurological conditions, elderly with pressure sores, dementia, liver and renal disease) and to a variety of settings (nursing homes and alternative care facilities, patient homes and changes in settings, e.g. discharges from hospital to home). Ideally, the research issues mentioned earlier should be investigated by randomized controlled trials involving adequate sample sizes and homogeneous groups of patients (type and stage of specific diseases; different categories of nutritional status and weight loss) so that study findings can more easily and with confidence be incorporated into clinical practice.

\section{Acknowledgements}

I would like to thank Dr Marinos Elia and the Malnutrition Advisory Group of the British Association for Enteral and Parenteral Nutrition.

\section{References}

Allan JD, Mason A \& Moss AD (1973) Nutritional supplementation in treatment of cystic fibrosis of the pancreas. American Journal of Diseases of Children 126, 22-26.

Altman DG (1991) Practical Statistics for Medical Research. London: Chapman and Hall.

Arnold C \& Richter M (1989) The effect of oral nutritional supplements on head and neck cancer. International Journal of Radiation Oncology 16, 1595-1599.

Berry HK, Kellogg FW, Hunt MM, Ingberg RL, Richter L \& Gutjahr C (1975) Dietary supplement and nutrition in children with cystic fibrosis. American Journal of Diseases of Children 129, 165-171.

Breslow RA, Hallfrisch J, Guy DG, Crawley B \& Goldberg AP (1993) The importance of dietary protein in healing pressure ulcers. Journal of the American Geriatrics Society 41, 357-362.

Cederholm TE \& Hellstrom KH (1995) Reversibility of proteinenergy malnutrition in a group of chronically-ill elderly outpatients. Clinical Nutrition 14, 81-87.

Chlebowski RT, Beall G, Grosvenor M, Lillington L, Weintraub N, Ambler C, Richards EW, Abbruzzese BC, McCamish MA \& Cope FO (1993) Long-term effects of early nutritional support with new enterotropic peptide-based formula vs. standard enteral formula in HIV-infected patients: Randomized, prospective trial. Nutrition 9, 507-512.

Department of Health (1991-7) Prescription Cost Analysis, England. London: Government Statistical Service, Department of Health.
Dickersin K, Scherer R \& Lefebvre C (1994) Identifying relevant studies for systematic reviews. British Medical Journal 309, 1286-1291.

Donahoe M, Rogers RM, Openbrier DR \& Wilson DO (1989) Effect of calorie intake on muscle strength and walking distance in malnourished COPD. American Review of Respiratory Disease 139, A334.

Douglass HO, Milliron S, Nava H, Eriksson B, Thomas P, Novick A \& Holyoke ED (1978) Elemental diet as an adjuvant for patients with locally advanced gastrointestinal cancer receiving radiation therapy: a prospectively randomized study. Journal of Parenteral and Enteral Nutrition 2, 682-686.

Efthimiou J, Fleming J, Gomes C \& Spiro SG (1988) The effect of supplementary oral nutrition in poorly nourished patients with chronic obstructive pulmonary disease. American Review of Respiratory Disease 137, 1075-1082.

Elia M \& Lunn PG (1996) Biological markers of protein-energy malnutrition. Clinical Nutrition 16, Suppl. 1, 1-46.

Elkort RJ, Baker FL, Vitale JJ \& Cordano A (1981) Long-term nutritional support as an adjunct to chemotherapy for breast cancer. Journal of Parenteral and Enteral Nutrition 5, 385-390.

Evans WK, Nixon DW, Daly JM, Ellenberg SS, Gardner L, Wolfe E, Shepherd FA, Feld R, Gralla R, Fine S, Kemeny N, Jeejeebhoy KN, Heymsfield S \& Hoffman FA (1987) A randomized study of oral nutritional support versus ad lib nutritional intake during chemotherapy for advanced colorectal and non-small cell lung cancer. Journal of Clinical Oncology 5, $113-124$.

Fiatarone MA, O’Neill EF, Ryan ND, Clements KM, Solares GR, Nelson ME, Roberts SB, Kehayias JJ, Lipsitz LA \& Evans WJ (1994) Exercise training and nutritional supplementation for physical frailty in very elderly people. New England Journal of Medicine 330, 1769-1775.

Foster KJ, Brown MS, Alberti KGMM, Buchanan RB, Dewar P, Karran SJ, Price CP \& Wood PJ (1980) The metabolic effects of abdominal irradiation in man with and without dietary therapy with an elemental diet. Clinical Radiology 31, 13-17.

Fuenzalida CE, Petty TL, Jones ML, Jarrett S, Harbeck RJ, Terry RW \& Hambidge KM (1990) The immune response to shortterm nutritional intervention in advanced chronic obstructive pulmonary disease. American Review of Respiratory Disease 142, 49-56.

Gray-Donald K, Payette H \& Boutier V (1995) Randomized clinical trial of nutritional supplementation shows little effect on functional status among free-living elderly. Journal of Nutrition 125, 2965-2971.

Gray-Donald K, Payette H, Boutier V \& Page S (1994) Evaluation of the dietary intake of homebound elderly and the feasibility of dietary supplementation. Journal of the American College of Nutrition 13, 277-284.

Harries AD, Jones LA, Danis V, Fifield R, Heatley RV, Newcombe RG \& Rhodes J (1983) Controlled trial of supplemented oral nutrition in Crohn's disease. Lancet i, 887-890.

Hellerstein MK, Pelfini A, Hoa R, Clinton R, Faix R, Richards EW, Abbruzzese BC, McCamish MA \& Cope FO (1994) A fully randomised, prospective, double-blind short-term trial contrasting the use of a novel enterotropic peptide-based formula and the current standard of practice enteral formula in HIV and AIDS patients: evaluation of multiple clinical parameters. Journal of Parenteral and Enteral Nutrition 18, 25S.

Hirsch S, Bunout D, De La Maza P, Iturriaga H, Petermann M, Icazar G, Gattas V \& Ugarte G (1993) Controlled trial on nutrition supplementation in outpatients with symptomatic alcoholic cirrhosis. Journal of Parenteral and Enteral Nutrition 17, 119-124. 
James WPT \& Ralph A (eds) (1992) The Functional Significance of Low Body Mass Index. Proceedings of an I/D/E/C/G Workshop. Rome, Italy: Nestlé Foundation.

Jensen MB \& Hessov IB (1997) Dietary supplementation at home improves the regain of lean body mass after surgery. Nutrition 13, 422-430.

Keele AM, Bray MJ, Emery PW, Duncan HD \& Silk DBA (1997) Two phase randomised controlled clinical trial of postoperative oral dietary supplements in surgical patients. Gut 40, 393-399.

Kirschner BS, Klich JR, Kalman SS, DeFavaro MV \& Rosenberg IH (1981) Reversal of growth retardation in Crohn's disease with therapy emphasizing oral nutritional restitution. Gastroenterology 80, 10-15.

Kissileff HR (1985) Effects of physical state (liquid-solid) of foods on food intake: procedural and substantive contributions. American Journal of Clinical Nutrition 42, 956-965.

Knowles JB, Fairbarn MS, Wiggs BJ, Chan-Yan C \& Pardy RL (1988) Dietary supplementation and respiratory muscle performance in patients with COPD. Chest 93, 977-983.

Kuhlmann MK, Schmidt F \& Kohler H (1997) Oral nutritional support in malnourished HD-patients. Preliminary results of a randomised controlled study. Journal of the American Society of Nephrology 8, 199A.

Lewis MI, Belman MJ \& Dorr-Uyemura L (1987) Nutritional supplementation in ambulatory patients with chronic obstructive pulmonary disease. American Review of Respiratory Disease 135, 1062-1068.

Lipschitz DA, Mitchell CO, Steele RW \& Milton KY (1985) Nutritional evaluation and supplementation of elderly subjects participating in a 'Meals on Wheels' program. Journal of Parenteral and Enteral Nutrition 9, 343-347.

Lynch K, Henry DA, Roberts C \& Coburn JW (1983) Clinical trial with oral carbohydrate supplement in hemodialysis patients: A nutritional evaluation. Dialysis and Transplantation 12, 566-568.

McManus RJ, Wilson S, Delaney BC, Fitzmaurice DA, Hyde CJ, Tobias RS, Jowett S \& Hobbs FDR (1998) Review of the usefulness of contacting other experts when conducting a literature search for systematic reviews. British Medical Journal 317, 1562-1563.

Malagelada J-R, Go VLW \& Summerskill WHJ (1979) Different gastric, pancreatic, and biliary responses to solid-liquid or homogenized meals. Digestive Disease and Sciences 24, 101-110.

Meredith CN, Frontera WR, O’Reilly KP \& Evans WJ (1992) Body composition in elderly men: effect of dietary modification during strength training. Journal of the American Geriatrics Society 40 , 155-162.

Nayel H, El-Ghoneimy E \& El-Haddad S (1992) Impact of nutritional supplementation on treatment delay and morbidity in patients with head and neck tumours treated with irradiation. Nutrition 8, 13-18.

Norregaard O, Tottrup A, Saaek A \& Hessov I (1987) Effects of oral nutritional supplements to adults with chronic obstructive pulmonary disease. Clinical Respiratory Physiology 23, Suppl. $12,388 \mathrm{~S}$.

Otte KE, Ahlburg P, D’ Amore F \& Stellfeld M (1989) Nutritional repletion in malnourished patients with emphysema. Journal of Parenteral and Enteral Nutrition 13, 152-156.

Ovesen L \& Allingstrup L (1992) Different quantities of two commercial liquid diets consumed by weight-losing cancer patients. Journal of Parenteral and Enteral Nutrition 16, 275-278.

Parsons HG, Beaudry P, Dumas A \& Pencharz PB (1983) Energy needs and growth in children with cystic fibrosis. Journal of Pediatric Gastroenterology and Nutrition 2, 44-49.
Pichard C, Sudre P, Karsegard V, Yerly S, Slosman DO, Delley V, Perrin L, Hirschel B \& Swiss HIV Cohort study (1998) A randomized double-blind controlled study of 6 months of oral nutritional supplementation with arginine, omega- 3 fatty acids in HIV-infected patients. AIDS 12, 53-63.

Plata-Salaman C (1996) Anorexia during acute and chronic disease. Nutrition 12, 69-78.

Pliner PL (1973) Effect of liquid and solid preloads on eating behaviour of obese and normal persons. Physiology and Behavior 11, 285-290.

Poppit SD \& Prentice AM (1996) Energy density and its role in the control of food intake: evidence from metabolic and community studies. Appetite 26, 153-174.

Rabeneck L, Palmer A, Knowles JB, Seidehamel RJ, Harris CL, Merkel KL, Risser JMH \& Akrabawi SS (1998) A randomized controlled trial evaluating nutrition counseling with or without oral supplementation in malnourished HIV-infected patients. Journal of the American Dietetic Association 98, 434-438.

Ramsey BW, Farrell PM, Pencharz P \& Consensus Committee (1992) Nutritional assessment and management in cystic fibrosis: a consensus report. American Journal of Clinical Nutrition 55, 108-116.

Rogers RM, Donahoe M \& Costantino J (1992) Physiologic effects of oral supplemental feeding in malnourished patients with chronic obstructive pulmonary disease. American Review of Respiratory Disease 146, 1511-1517.

Schurch B \& Scrimshaw NS (eds) (1987) Chronic Energy Deficiency: Consequences and Related Issues. Background papers and working group reports presented at an I/D/E/C/G meeting of August 3-7, 1987. Rome, Italy: Nestlé Foundation.

Shepherd RW, Thomas BJ, Bennett D, Cooksley WGE \& Ward LC (1983) Changes in body composition and muscle protein degradation during nutritional supplementation in nutritionally growth-retarded children with cystic fibrosis. Journal of Pediatric Gastroenterology and Nutrition 2, 439-446.

Simko V (1983) Long-term tolerance of a special amino acid oral formula in patients with advanced liver disease. Nutrition Reports International 27, 765-773.

Skypala IJ, Ashworth FA, Hodson ME, Leonard CH, Knox A, Hiller EJ, Wolfe SP, Littlewood JM, Morton A, Conway S, Patchell C, Weller P, McCarthy H, Redmond A \& Dodge J (1998) Oral nutritional supplements produce significant weight gain in cystic fibrosis patients. Journal of Human Nutrition and Dietetics 11, 95-104.

Sondel SA, Parrell SW, Becker D \& Mischler EH (1987) Oral nutritional supplementation in cystic fibrosis. Nutritional Support Services 7, 20-22.

Stauffer JL, Carbone JE \& Bendoski MT (1986) Effects of diet supplementation on anthropometric and laboratory nutritional parameters in malnourished ambulatory patients with severe chronic obstructive pulmonary disease (COPD). American Review of Respiratory Disease 133, A204.

Stratton RJ \& Elia M (1999a) A critical systematic analysis of the use of oral nutritional supplements in the community. Clinical Nutrition 18, Suppl. 2, 29-84.

Stratton RJ \& Elia M (1999b) The effects of enteral tube feeding and parenteral nutrition on appetite sensations and food intake in health and disease. Clinical Nutrition 18, 63-70.

Stubbs RJ (1992) Macronutrients, appetite and energy balance in humans. PhD Thesis, University of Cambridge.

Stubbs RJ, Johnstone AM, O'Reilly LM, Barton K \& Reid C (1998) The effect of covertly manipulating the energy density of mixed diets on ad libitum food intake in 'pseudo free-living' humans. International Journal of Obesity 22, 980-987.

Tisdale MJ (1997) Cancer cachexia: Metabolic alterations and clinical manifestations. Nutrition 13, 1-7. 
Tolia V (1995) Very early onset nonorganic failure to thrive in infants. Journal of Pediatric Gastroenterology and Nutrition 20, 73-80.

Volkert D, Hubsch S, Oster P \& Schlierf G (1996) Nutritional support and functional status in undernourished geriatric patients during hospitalization and 6-month follow-up. Aging Clinical and Experimental Research 8, 386-395.

Welch PK, Dowson M \& Endres JM (1991) The effect of nutrient supplements on high risk long term care residents receiving pureed diets. Journal of Nutrition for the Elderly $\mathbf{1 0}$, 49-62.
Wilson DO, Rogers RM, Sanders MH, Pennock BE \& Reilly JJ (1986) Nutritional intervention in malnourished patients with emphysema. American Review of Respiratory Disease 134, 672-677.

Woo J, Ho SC, Mak YT, Law LK \& Cheung A (1994) Nutritional status of elderly patients during recovery from chest infection and the role of nutritional supplementation assessed by a prospective randomized single-blind trial. Age and Ageing 23, 40-48. Yassa JG, Prosser R \& Dodge JA (1978) Effects of an artificial diet on growth of patients with cystic fibrosis. Archives of Diseases in Childhood 53, 777-783.

(C) Nutrition Society 2000 